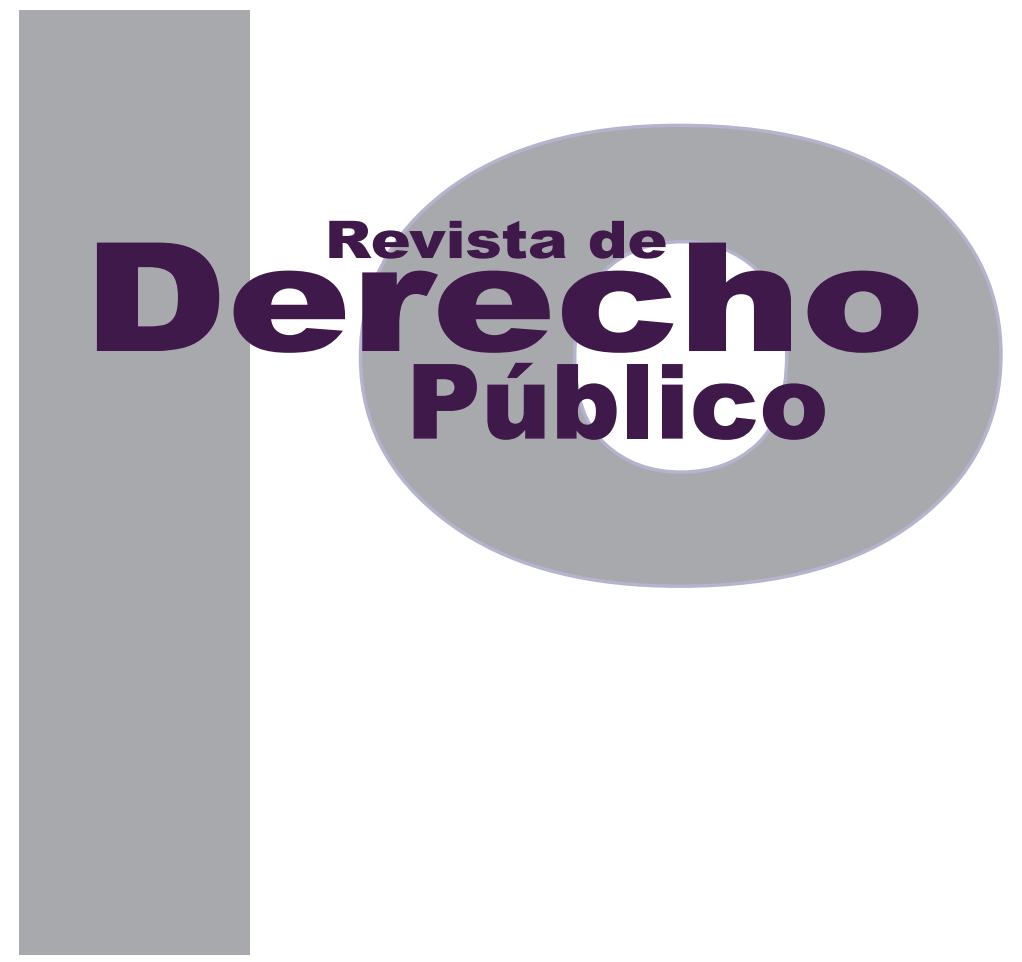

\title{
INDÍGENAS EN LA CIUDAD. CONSTRUCCIÓN Y MANTENIMIENTO DE LA IDENTIDAD EN CONTEXTOS URBANOS A PARTIR DEL DESPLAZAMIENTO FORZADO
}

\author{
Silvia Catalina QUintero ToRReS \\ LAURA NATALIA VARgas MORA
}

Universidad de los Andes

Facultad de Derecho

Revista de Derecho Público N. ${ }^{\circ} 31$

Julio - Diciembre de 2013. ISSN 1909-7778 


\title{
Indígenas en la ciudad. Construcción y mantenimiento de la identidad en contextos urbanos a partir del desplazamiento forzado*
}

\author{
Silvia Catalina Quintero Torres** \\ Laura Natalia Vargas Mora***
}

\begin{abstract}
RESUMEN
El conflicto armado que vive Colombia le ha significado múltiples afectaciones a la población civil. Un sector que se ha visto perjudicado de manera alarmante son las comunidades indígenas rurales. Tradicionalmente, esta afectación se ha concentrado en el efecto perverso del fenómeno, entendido como el cambio abrupto de contexto y las posteriores dificultades socioeconómicas, así como en su situación previa al daño. Este texto pretende mostrar que la manera dominante en la que el derecho se ha aproximado a la identidad, en lo relacionado con las comunidades indígenas, ha sido a través de su esencialismo, concepto transversal en la corriente
\end{abstract}

\begin{abstract}
The long-running conflict that threatens Colombia has had multiple effects on civilian population. Among the most affected by this phenomenon we find the indigenous communities. Traditionally, this impact has focused on the negative effect derived from this phenomenon, understood as the abrupt living change as well as the later economic difficulties, and their situation prior to the damage. With this been said, this text aims to illustrate that the dominant approach to indigenous identity, has been trough essentialism, a key concept in the context of liberal multiculturalism. This is accomplished by analyzing the general situation of some indigenous communi-
\end{abstract}

Cómo citar este artículo: Quintero Torres, S. C. y Vargas Mora, L. N. (Diciembre, 2013). Indígenas en la ciudad. Construcción y mantenimiento de la identidad en contextos urbanos a partir del desplazamiento forzado. Revista de Derecho Público, 31

Este artículo corresponde a una versión ampliada del trabajo desarrollado en el seminario Multiculturalismo y justicia transicional, de la Maestría en Derecho de la Universidad de los Andes, a cargo del profesor Libardo José Ariza, a quien expresamos nuestro más sincero agradecimiento por sus comentarios, recomendaciones y aportes a versiones previas de este escrito. Así mismo, queremos agradecer especialmente a Catalina Mejía por las recomendaciones bibliográficas y comentarios.

". Estudiante de pregrado en Derecho y Antropología de la Universidad de los Andes. Correo: sc.quintero177@uniandes.edu.co

.... Estudiante de pregrado en Derecho y Literatura de la Universidad de los Andes. Correo: In.vargas130@uniandes.edu.co 
del multiculturalismo liberal. Lo anterior se hace mediante el análisis de la situación de desplazamiento forzado de la que muchas comunidades indígenas han sido víctimas. Finalmente, se busca analizar algunas limitaciones que implica esta visión de la identidad en la construcción de políticas públicas, en respuesta al fenómeno del desplazamiento, con un enfoque transformador.

Palabras clave: identidad, esencialismo, multiculturalismo, comunidades indígenas, desplazamiento forzado, reparación para daño cultural, Ley 1448 de 2011. ties that have been forcibly displaced. Finally, we seek to analyze some limitations that this concept of identity entails in the construction of public policies, in response to displacement, with a transformative approach.

KEY WORDS:identity, essentialism, multiculturalism, indigenous communities, forced displacement, reparations for cultural loss, Law 1448 of 2011. 


\section{SUMARIO}

Introducción - I. CONTEXTO: EL DESPLAZAMIENTO INDÍGENA - II. DESPLAZAMIENTO FORZADO Y NORMATIVIDAD FRENTE A LO INDÍGENA - III. IDENTIDAD INDÍGENA - A. Identidad jurídica: elemento subjetivo y objetivo - B. Debate sobre la identidad indígena en contextos urbanos - IV. REPARACIÓN PARA EL DAÑO CULTURAL COLECTIVO PRODUCTO DEL DESPLAZAMIENTO FORZADO - V. CONCLUSIÓN - Referencias bibliográficas. 
A pesar de las diferencias que existen entre ellas, tanto la injusticia socioeconómica como

la injusticia cultural se encuentran ampliamente difundidas en las sociedades contemporáneas. Ambas están arraigadas en procesos y prácticas que sistemáticamente ponen a unos grupos de personas en desventaja, frente a otros. Ambas, por lo tanto, deben ser remediadas. Nancy Fraser

\section{Introducción}

El indígena en la ciudad escapa del ideario general. Así de años atrás la presencia de múltiples comunidades indígenas que deambulan por el centro de Bogotá y de otras urbes colombianas haya venido en aumento, es una situación chocante que puede rayar en lo ilógico para el común de los habitantes de la ciudad. ${ }^{1}$ Sin embargo, esta es una tendencia en aumento, sea por causa del desplazamiento forzado, por la búsqueda de mejores condiciones de subsistencia, por procesos de reemergencia étnica, por razones transitorias o por otra infinidad de causas.

Este texto pretende mostrar que la esencialización y el establecimiento de criterios tangibles ha sido la forma dominante en la que el derecho se ha aproximado a la identidad indígena fuera del contexto del resguardo, asumiendo que está relacionada, de forma intrínseca, con el resguardo y el territorio donde se encuentran ubicados.

1 Como se verá más adelante, las consideraciones de la Corte Constitucional, al igual que las mostradas en medios de comunicación, indican que el ideal para las comunidades indígenas que habitan actualmente en Bogotá y otras grandes ciudades es el retorno a sus territorios.
Para probarlo se parte del análisis de la situación de desplazamiento forzado del que muchas comunidades indígenas han sido víctimas, y cuya reparación se ha enfocado principalmente en el retorno y restitución del terreno del que fueron despojados. Luego se analizan algunas limitaciones que la aproximación esencialista trae consigo, para evidenciar que esa forma de reparación, si bien es válida e importante, no debe ser la única opción viable para los sujetos colectivos y étnicos.

Por lo anterior, en la sección Contexto: el desplazamiento indígena se hace referencia al fenómeno del desplazamiento forzado, partiendo de la caracterización oficial y la cita de cifras y datos gubernamentales. A continuación, en el aparte Desplazamiento forzado y normatividad frente a lo indígena se muestra el impacto de este fenómeno en algunas comunidades indígenas y la migración a la ciudad. Luego, en Identidad indígena, se trata la transformación de la concepción jurídica de la identidad indígena en contextos urbanos, como consecuencia del desplazamiento forzado, mediante el análisis de parte de la normatividad, la jurisprudencia y los debates respecto a la aproximación a la identidad. Posteriormente, en Reparación para el daño cultural colectivo, producto del desplazamiento forzado, se rescatan propuestas para la reparación del daño al sujeto étnico colectivo e individual a partir de una complejización del concepto de identidad. Finalmente, se concluye retomando la importancia de la aproximación crítica a la visión esencialista de la identidad, propia del discurso multicultural liberal. 


\section{CONTEXTO: EL DESPLAZAMIENTO INDÍGENA}

Para comenzar es pertinente hacer un barrido general por la información oficial referente a la situación actual de las comunidades, en relación con el desplazamiento. Así, de acuerdo con el Informe del Gobierno Nacional a la Corte Constitucional sobre los avances en la superación del estado de cosas inconstitucional, ${ }^{2}$ declarado mediante la sentencia T-025 de 2004, el $11 \%$ de la población en situación de desplazamiento se identifica como parte de alguna mi-
Como se aprecia en la gráfica 1, Bogotá ocupa el segundo lugar en cuanto a recepción de indígenas en situación de desplazamiento, con un total de 6.739 indígenas, esto es, el 23\% del total de la población desplazada que ha llegado a la ciudad, una cifra bastante significativa ${ }^{3} \mathrm{si}$ se mira que la población indígena representa el $2.74 \%$ del total de la población colombiana (ACNUR, 2012, p. 1). Esto evidencia el fuerte y preocupante impacto que tiene el desplazamiento sobre las poblaciones indígenas.

Gráfica 1

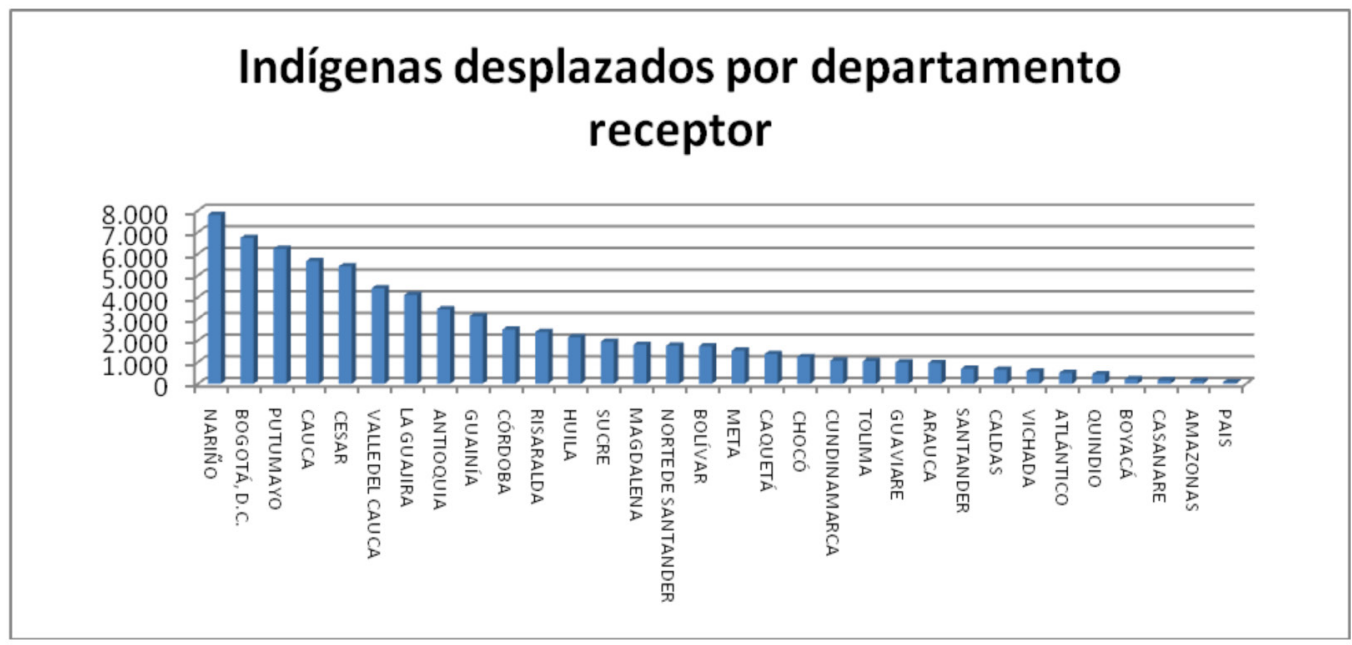

noría étnica, y de este el $2 \%$ se reconoce como parte de pueblos indígenas, lo que corresponde a 74.317 personas. Si bien esta cifra no pareciera ser mayoritaria, es considerable teniendo en cuenta que, de acuerdo con el último censo general (2005) del Departamento Administrativo Nacional de Estadística (DANE), para ese año 1.392.623 individuos se autoidentificaban como pertenecientes a comunidades indígenas.

2 Este concepto se explicará más adelante.
Fuente: Registro Único de Población Desplazada (RUPD), 30 de septiembre de 2009.

Procesado: Unidad de Desarrollo de Política Pública sobre Desplazamiento Forzado.

3 El auto 004 de 2009 (Corte Constitucional), citando la comunicación de la Organización Nacional Indígena de Colombia (ONIC) de 2006, da cuenta que la mayor parte $(93.37 \%)$ de resguardos indígenas han sufrido el desplazamiento de su población. Esto muestra la grave incidencia que ha tenido el conflicto armado, y en especial el desplazamiento forzado sobre las comunidades indígenas. 
Teniendo como fundamento las cifras anteriormente presentadas, es preciso referirse a la necesidad de reubicación, temporal o permanente, y las consecuencias socioeconómicas que deben afrontar estas comunidades en el área urbana. El desplazamiento, sumado a la estratificación socioeconómica de la urbe bogotana, ha obligado a los indígenas que migran hacia la capital del país como producto de la violencia o de amenaza de esta a asentarse en sectores de estrato socioeconómico bajo (Secretaría de Integración Distrital, 2011, p. 34). En esto la población indígena no corre una suerte distinta a la de la gran mayoría de la población colombiana víctima del desplazamiento, que por falta de recursos económicos debe ubicarse en zonas marginales donde el costo de vida es más bajo.

Al respecto, la Secretaría de Integración Distrital (2012, p. 4) ha hecho énfasis en la gravedad de las condiciones de subsistencia de las comunidades indígenas que llegan a la urbe bogotana:

gran parte de las familias viven dispersas en los barrios más pobres de la periferia y del centro de la ciudad, compartiendo con los demás habitantes los problemas económicos y las dificultades para acceso a servicios de seguridad social, educación, salud, empleo, vivienda y servicios públicos. En general, la población indígena residente en la ciudad se concentra en la localidad de Suba (23,3\%), seguida por Bosa (12,9\%), Engativá (10\%) y Kennedy (6.2\%).

Pero estas localidades no son las únicas -también hay presencia indígena en las localidades de Usme, Ciudad Bolívar y Santa Fe-como tam- poco son solo esas las dificultades. Como lo reitera la Secretaría de Integración Distrital (2011, p. 24), hay necesidad de asegurarles una forma de subsistencia, pues si bien muchos se ayudan tejiendo o vendiendo cosas por las calles del centro de Bogotá, la falta de educación les impide el acceso a empleos formales y los somete a una situación de pobreza y precariedad.

Según la Fundación Hemera (2006), las condiciones de vida de la población indígena víctima del desplazamiento "no son las óptimas para un estándar de vida adecuado. De hecho, un 30\% de los encuestados presentan necesidades en todos los niveles de servicios sociales, y el 95\% afirma vivir en arriendo en estratos bajos de la ciudad, lo cual refleja deficiencias en la calidad de vida y la deficiencia en la asistencia del Estado para garantizar el acceso a los servicios. Igualmente, la constante fue la necesidad de empleo y vivienda".

A partir del anterior panorama general conviene hacer una referencia expresa a la forma en la cual la normatividad y la jurisprudencia se han aproximado al fenómeno del desplazamiento forzado, en particular, en el caso de las comunidades indígenas.

\section{DESPLAZAMIENTO FORZADO Y NORMATIVIDAD FRENTE A LO INDÍGENA}

La historia indígena no solo en Colombia ha estado atravesada por episodios de violencia y marginalización: 
Mientras que en los primeros años de organización y auge del movimiento indígena la violencia es ejercida por gamonales, terratenientes y narcotraficantes que emplean estrategias paramilitares para consolidar su poder local y territorial, con el protagonismo que adquieren tras la Reforma de 1991, la influencia de las organizaciones indígenas alcanza el ámbito nacional y, por eso mismo, el conflicto armado los alcanza con toda su magnitud. En la medida en que los pueblos indígenas representan una frontera poderosa para la expansión y el control territorial de los grupos armados, sus territorios y poblaciones se han convertido en escenarios de guerra (Ariza, 2009, p. 269).

Su posicionamiento geográfico y económico, entre otros factores, ha contribuido a que, como lo establece Ariza en el pasaje anterior, se encuentren muchas veces en medio del conflicto armado o de los intereses económicos de grandes empresas o terratenientes. De la misma manera, como lo refiere Villa, "en la medida que los pueblos indígenas en Colombia consolidan una visión territorial y disponen de territorio donde de forma relativa ejercen gobierno, a la vez y ante la intensificación del conflicto, se experimentan en medio de los ejércitos que avanzan en procura de ejercer control sobre áreas definidas como estratégicas desde visiones antagónicas" (2005, p. 20). Aun cuando el movimiento social indígena en la actualidad, como se verá más adelante, ha cobrado fuerza, esto no obsta ni ha impedido la grave y constante violencia que se da sobre sus pueblos.

Partiendo de lo anterior, es entonces necesario hacer referencia a la normatividad nacional que abarca lo relacionado con las comunidades indígenas, con el objetivo de ver de qué forma se ha aproximado el Estado a este sujeto y las respuestas que ha brindado a las condiciones particulares que rodean su situación.

En primer lugar, cabe rescatar que con el siglo XX se transformó la predominante visión evolucionista por una más horizontal, donde las comunidades tradicionales indígenas ya no son vistas como salvajes sin civilización o sociedad. En documentos como los Convenios 107 de 1957 y 169 de 1989 de la Organización Internacional del Trabajo (оाт), se reconoce la existencia de estos pueblos como comunidades en sí mismas, con prácticas culturales diferentes y valiosas que deberán ser protegidas y salvaguardadas, en vez de colonizadas y destruidas. La Constitución de 1991, como producto de un ambiente políticamente favorable y de las luchas de los movimientos indígenas consolidados en el momento (Ariza, 2009, p. 247) reconoce el carácter multicultural y pluriétnico de la nación colombiana, particularmente en los artículos 7 y 8 que hacen referencia a la existencia de las comunidades indígenas y su riqueza étnica y cultural estableciendo, como deber del Estado, su protección y salvaguarda.

A partir de las disposiciones constitucionales que reconocen la existencia de los resguardos indígenas y establecen que estos "son de propiedad colectiva y no enajenable" (Constitución Política, art. 329), se expide la Ley 160 de 1994 y su respectivo Decreto reglamentario número 2164 de 1995, que regulan, entre otras cosas, la constitución de resguardos indígenas. De 
esta manera, se da reconocimiento material a la autonomía y diferenciación cultural de las comunidades indígenas y se busca otorgarles una prerrogativa territorial, un derecho que por vía jurisprudencial se determinó como fundamental y que recae sobre la comunidad como sujeto colectivo, para preservar su existencia y su diferencia cultural.

Sin embargo, esta autonomía y el subsiguiente reconocimiento del Estado se han visto vulnerados por el constante conflicto armado y las pugnas dentro de las que se ven envueltas por su posicionamiento sociogeográfico y político. Como ejemplo de esto, cabe mencionar que en la actualidad no solo los actores armados, sino actores legales influenciados por motivaciones de carácter económico han tratado de apropiarse de una forma u otra de los terrenos ocupados por ellas. ${ }^{4}$ En relación con el conflicto, de acuerdo con Villa y Houghton (2005), para 2003 “el hecho más relevante de este año es la aparición de las fuerzas militares y los paramilitares como responsables de más del 83\% de los desplazamientos masivos, el 55\% bajo responsabilidad de los primeros y $27 \%$ por parte de los segundos." Los territorios se transforman en lugares inseguros que en nada se parecen al ideal generalizado y romántico del resguardo, con el que las comunidades tienen esa relación particular, que se asume como casi simbiótica. El producto de esto ha sido la migración dentro de la zona

4 Véanse los casos del pueblo Emberá-Katío y la construcción de la represa Urrá I, la pugna entre la comunidad Sikuani y la petrolera Pacific Rubiales, así como las empresas de agrocombustibles brasileras y japonesas presentes en la zona cercana a sus resguardos. rural y hacia la urbe de muchos individuos pertenecientes a distintas comunidades indígenas.

Dada la magnitud de este fenómeno y su permanencia en el tiempo, en 1997 se expidió la Ley 387 mediante la cual se buscó adoptar medidas para la prevención del desplazamiento forzado, así como la atención, protección, consolidación y estabilización socioeconómica de los desplazados internos por la violencia en el país. Sin embargo, esta se dirigió a la población en situación de desplazamiento en general. Si bien la norma en el numeral 8 del artículo 10 establece lo que podría considerarse un esbozo de enfoque diferencial, ${ }^{5}$ este no tiene ningún tipo de desarrollo material en sus decretos reglamentarios, lo que evidencia el insuficiente despliegue de institucionalidad estatal a la hora de dar respuesta efectiva a los graves problemas que trae consigo el desplazamiento forzado de comunidades étnica y culturalmente diferenciadas.

Con esta situación en mente, y en consideración a que la norma anteriormente mencionada no generó una disminución ni un trato adecuado al fenómeno del desplazamiento forzado, la Corte Constitucional declaró el Estado de Cosas Inconstitucional ${ }^{6}$ en materia de desplazamien-

5 "Garantizar atención especial a las comunidades negras e indígenas sometidas al desplazamiento en correspondencia con sus usos y costumbres, y propiciando el retorno a sus territorios".

6 Dentro de los factores valorados por la Corte para definir si existe un estado de cosas inconstitucional cabe destacar los siguientes: (i) la vulneración masiva y generalizada de varios derechos constitucionales que afecta a un número significativo de personas; (ii) la prolongada omisión de las autoridades en el cumplimiento de sus obligaciones para garantizar los derechos; (ii) la adopción de prácticas inconstitucionales, como la incorporación de la acción de tutela como parte del procedimiento para garantizar el derecho conculcado; (iii) la no expedición de medidas legislativas, administrativas o presupuestales necesarias 
to forzado en la sentencia T-025 de 2004. Así mismo, en el auto 004 de 2009 llamó la atención sobre el mayor riesgo que se cernía sobre los pueblos indígenas. Particularmente, el exterminio de algunas comunidades tanto desde el punto de vista cultural en razón al desplazamiento y dispersión de sus miembros como desde el punto de vista físico, debido a la muerte de sus integrantes por causas violentas, o por situaciones de salubridad, desnutrición o indebida atención en salud.

De igual manera, en referencia a la falta de respuesta estatal, visibilización y reacción con respecto a la particular afectación que enfrentan las comunidades indígenas la Corte afirmó:

Es una emergencia tan grave como invisible. Este proceso no ha sido reconocido aún en sus reales dimensiones, por las autoridades encargadas de preservar y proteger a los pueblos indígenas del país. Mientras que numerosos grupos indígenas son atacados, desplazados y desintegrados en todo el territorio nacional por los actores armados que operan en Colombia y por los distintos factores subyacentes al conflicto y vinculados al mismo, el Estado y la sociedad colombianos continúan preciándose de su carácter multicultural, de sus riquezas étnicas y de distintos aspectos de las culturas indígenas nacionales. Esta contradicción entre la realidad y la representación generalizada de dicha realidad ha sorprendido a la Corte Cons-

para evitar la vulneración de los derechos; (iv) la existencia de un problema social cuya solución compromete la intervención de varias entidades, requiere la adopción de un conjunto complejo y coordinado de acciones y exige un nivel de recursos que demanda un esfuerzo presupuestal adicional importante; ( $v$ ) si todas las personas afectadas por el mismo problema acudieran a la acción de tutela para obtener la protección de sus derechos, se produciría una mayor congestión judicial (Corte Constitucional. Sentencia T - 025 de 2004). titucional, no sólo por su crueldad inherente, sino por revelar una actitud de indiferencia generalizada ante el horror que las comunidades indígenas del país han debido soportar en los últimos años - indiferencia que en sí misma es un menosprecio de los postulados constitucionales básicos que nos rigen como Estado Social de Derecho fundado en el respeto de la diversidad étnica y cultural. (Corte Constitucional, auto 004 de 2009).

Siguiendo por esta línea, la Corte, en la misma providencia, llamó la atención sobre los riesgos de extinción presentes para muchas comunidades como producto del conflicto armado, entre ellas los Nukak Makú, algunas poblaciones indígenas del Guaviare, Wiwa, Wayuú, Awá, Koreguaje, entre otras, e instó al gobierno nacional a tomar medidas de carácter urgente y prioritario en el marco de su deber de protección y garante de estas.

Adicionalmente, la Corte identificó en el mismo auto,

una serie de factores comunes, que constituyen los troncos principales de la confrontación que se cierne sobre los pueblos indígenas del país y que, dependiendo del contexto geográfico, socioeconómico y cultural del cual se trate, se entrelazarán de manera distinta sobre cada comunidad en particular. Estos factores se agrupan en tres categorías principales:

(1) las confrontaciones que se desenvuelven en territorios indígenas entre los actores armados, sin involucrar activamente a las comunidades indígenas y sus miembros, pero afectándolos en forma directa y manifiesta; 
(2) los procesos bélicos que involucran activamente a los pueblos y comunidades indígenas, y a sus miembros individuales, en el conflicto armado; $y$

(3) los procesos territoriales y socioeconómicos conexos al conflicto armado interno que afectan sus territorios tradicionales y sus culturas. ${ }^{7}$ (Corte Constitucional, auto 004 de 2009).

Estos factores conforman ejes particulares que, a su vez, se traslapan de maneras distintas en cada comunidad afectada generando diversas consecuencias en el sujeto colectivo, en el orden individual o en la relación con el territorio y las prácticas culturales específicas. La relación que tendrá la comunidad afectada con el Estado, posterior a la vulneración, será distinta dependiendo del perjuicio particular y la reparación que se buscará irá enfocada al daño causado.

Con fundamento en la gravedad de la situación anteriormente expuesta, la Corte ordenó el diseño e implementación de un Programa de garantía de los derechos de los pueblos indígenas afectados por el desplazamiento, que debía contener componentes de prevención y atención e incluir un "enfoque diferencial, en este caso en cumplimiento del principio de diversidad etnocultural" (Corte Constitucional, auto 004 de 2009). A la vez, la Corte ordenó que las mismas entidades encargadas de llevar a cabo el programa anteriormente descrito diseñaran e implementaran "planes de salvaguarda étni-

7 Esto fue reiterado, recientemente, por la misma Corporación en la sentencia T-402 de 2011. ca ante el conflicto armado y el desplazamiento forzado para cada uno de los pueblos identificados en la presente providencia" con el fin de intervenir en la prevención del desplazamiento forzado de estas comunidades, así como dar respuesta a la crítica y preocupante situación actual de ellas. Así, estos planes debían: (i) ser consultados previamente con las comunidades beneficiarias; (ii) incluir medidas en términos de prevención del impacto producto del conflicto armado y atención inmediata y efectiva, con un enfoque de carácter diferencial; (iii) responder a los derechos fundamentales de las víctimas del conflicto armado, entendidos como justicia, verdad, reparación y garantías de no repetición; (iv) incluir un programa de protección para líderes y autoridades indígenas en riesgo; (v) prever herramientas para el fortalecimiento de la integridad cultural y social de cada etnia beneficiaria; (vi) brindar mecanismos de protección de los territorios tradicionales; (vii) prever que principal objetivo, ante la población indígena víctima del desplazamiento, debe ser la garantía de su retorno en condiciones de voluntariedad, seguridad y dignidad, entendiendo, a su vez, que en caso de amenaza o riesgo esta opción no debe ser la inicial.

Para ello, la Corte dio un plazo máximo de implementación de seis (6) meses, a partir de la expedición del auto. ${ }^{8}$ Sin embargo, para abril de 2010, como lo indican Rodríguez, Arias, Boada, Ordúz y Rubiano (2010, p. 30), el Gobierno estaba apenas socializando la sentencia T-025 de 2004 y su respectivo auto 004. A partir de lo

$8 \quad$ El auto fue emitido el 26 de enero de 2009. 
dispuesto en estas decisiones judiciales algunas comunidades solicitaron iniciar la elaboración del Programa de garantías y los planes de salvaguarda, luego de finalizar los encuentros departamentales programados. Sin embargo, la organización y la logística de estos eventos se realizaron de una forma muy poco diligente, con el resultado de que un año después no existía ni el Programa ni el cronograma para su implementación y seguimiento dispuesto por la Corte.

Ahora, para el 2011, según las sentencias T-282 y T-402 del mismo año, el panorama no había cambiado de forma sustancial. Por la situación sociopolítica del país y las circunstancias derivadas del conflicto armado,

existen etnias que se ven afectadas en forma cíclica y reiterativa por desplazamientos que obedecen a los mismos factores, caso por ejemplo de las comunidades Emberá-Katío, Emberá Dobidá, Awá o Wounaan, lo anterior de conformidad con lo señalado por este Tribunal Constitucional en el auto 004 de 2009, después de estudiar los informes presentados por diferentes entidades durante el proceso de monitoreo del cumplimiento de la Sentencia T-025 de 2004 y sus autos de seguimiento (Corte Constitucional. Sentencia T-402 de 2011).

En el caso de estas comunidades es claro que, pese a lo ordenado en el auto 004 de 2009, continúan en una situación de vulnerabilidad alarmante. Esto las convierte en sujetos de especial protección constitucional, situándolas en un contexto muy específico de requerimiento de atención y protección prioritario. La omisión de este deber podría llevar al exterminio a muchas de ellas, situación que, como bien lo expresa la Corte, contraviene el discurso multicultural que permea el texto constitucional y la misma idea simbólica de lo que es la nación colombiana en relación con la riqueza cultural y la existencia de pueblos indígenas dentro del territorio nacional. ${ }^{9}$

Debido a la falta de resultados concretos para aminorar el fenómeno del desplazamiento forzado, así como la necesidad de tomar medidas para mitigar y reparar los daños causados a la población afectada por el conflicto armado, el Congreso expidió en el mismo año la Ley 1448, denominada Ley de Víctimas y Restitución de Tierras. Esta le dio un reconocimiento distinto a los afectados por los hechos ocurridos con ocasión del conflicto: ya no son afectados o desplazados, sino víctimas, esto es, una identidad distinta, con mayor fuerza discursiva.

En este contexto y en atención especial a la particular situación de las comunidades indígenas se expide el Decreto-Ley 4633 de 2011, que desarrolla lo dispuesto en la Ley 1448 con un enfoque diferencial especialmente construido pensando en ellas. De acuerdo con el preámbulo, dentro de sus objetivos está el "garantizar sus derechos ancestrales, humanos y constitucionales, mediante medidas y acciones que les garanticen sus derechos colectivos e individuales, principalmente sus derechos territoriales, a la

9 El texto constitucional contiene varias referencias a la importancia de la protección de la diversidad cultural. El artículo 7 establece: "El Estado reconoce y protege la diversidad étnica y cultural de la Nación colombiana". Así mismo, el artículo 8 consagra la obligación de proteger las riquezas culturales y naturales de la Nación. De igual forma, el artículo 10 dispone que "Las lenguas y dialectos de los grupos étnicos son también oficiales en sus territorios. La enseñanza que se imparta en las comunidades con tradiciones lingüísticas propias será bilingüe". 
identidad, la autonomía, la autodeterminación, buen vivir y su estrategia de vida para la permanencia cultural y pervivencia como pueblos". Ello implica una consideración particular, un enfoque diferente a la hora de diseñar los mecanismos de restitución y reparación de los daños generados por el conflicto armado en los pueblos y comunidades indígenas. Se da prelación a los derechos en cabeza del sujeto colectivo, derechos ancestrales, territoriales. Es importante resaltar que en este decreto se concibe la reparación con carácter transformador, que busca resarcir y contribuir a cambiar las estructuras de discriminación y marginalización previas al conflicto armado. Este tema y su relación con la identidad y reparación a estas comunidades serán tratados a profundidad en la conclusión del presente texto.

Lo anterior se ve materializado, de acuerdo con la Unidad para la Atención y Reparación Integral a las Víctimas (2012), en el diseño de una ruta de reparación colectiva que, además de las seis instancias genéricas -registro, alistamiento, diagnóstico del daño, formulación del plan de reparación colectiva, implementación del plan y seguimiento al mismo- considera, para los grupos étnica y culturalmente diferenciados, escenarios de preconsulta y la consulta previa. Como se ve, se han creado mecanismos para el tratamiento y reparación que tienen en cuenta los elementos particulares de las minorías étnicas. Se busca reconocer la diferencia de las comunidades indígenas, como sujetos colectivos e individuales, y desarrollar herramientas particulares en consideración a sus necesidades y requerimientos específicos.
En este punto es necesario resaltar que el discurso normativo y jurisprudencial en torno a comunidades indígenas se ha dado en función de identidad, pues, como se verá más adelante, es la categoría que permite determinar de manera "concreta"10 cómo se implementan las normas diferenciadas y a quienes se les aplican. Este concepto es transversal a toda la normatividad que trata sobre derechos y deberes de comunidades étnica y culturalmente diferenciadas, pues de él depende su aplicación o inaplicación a ciertos sujetos. Por ello, a continuación se procede a explicar y analizar la forma en la cual se ha entendido esta identidad.

\section{IDENTIDAD INDÍGENA}

Tradicionalmente, la aproximación a la identidad indígena, en el contexto de la corriente multiculturalista liberal, se da por medio de características que se asumen como esenciales: un sujeto colectivo, una lengua común, una historia compartida, una relación especial casi simbiótica con un territorio, y que permiten una diferenciación prácticamente evidente a primera vista. Aquel que cumpla con estas particularidades podrá ser considerado como indígena. ${ }^{11}$ Sin em-

10 El uso de comillas responde a una aproximación propia. Esta clasificación identitaria permite establecer criterios para diferenciar y categorizar a los sujetos, así como simplificar el otorgamiento de ciertos derechos y obligaciones diferenciados, en función de su etnicidad.

11 Además de esto, desde la Colonia y mucho antes, se ha recurrido a la diferenciación con base en rasgos particulares, físicos: "El indio puro, pues, se puede identificar con base en la presencia de ciertas características físicas como la estatura, la forma de la espalda, las cuales son complementadas por rasgos indiscutibles de la personalidad indígena como la malicia, el temor y la desconfianza" (Ariza, 2009, p. 166). Este pasaje hace referencia a la insaciable búsqueda de Manuel Ancizar por encontrar indios puros, en la cual trazó algunas líneas de identificación que le permitieran dilucidar cuándo estaría frente a un puro. 
bargo, la construcción de la identidad indígena no es unilateral, tiene dos aristas: la autoidentificación, propia de los sujetos individuales que se reconocen como indígenas, y la heteroidentificación, característica de una sociedad mayoritaria que reconoce a esos sujetos y colectividades como indígenas, con el fin de otorgarles prerrogativas y deberes. En esta última se parte del supuesto que somos distintos, a partir de las diferencias; de esa alteridad es que ocurre la identificación, la clasificación.

Con el objeto de criticar esta concepción unidimensional de la identidad, en términos de Herbert Marcuse, conviene traer el análisis de Bocarejo (2011) sobre la política multicultural colombiana. Según esta autora, el principal poder de esta corriente "radica en definir o redefinir aqueIlos sujetos que se consideran como los otros de la nación, o mejor aún, aquellos que construyen su pluralidad. El reconocimiento de los grupos étnicos tuvo y sigue teniendo como premisa la supervivencia de unas culturas que se piensan como autóctonas, y es precisamente esa diferencia la que se busca valorar en el multiculturalismo colombiano". En su concepto, se parte de la diferencia, de aquellas características que distinguen a un sujeto indígena de uno que no lo es, para definir lo que es ser indígena, su identidad. Bajo el presupuesto del multiculturalismo esa diferencia se exalta, se busca mantener en el tiempo: preservar la existencia de una identidad estática, dada, de las comunidades étnicas, en vez de considerar que la constitución actual de esta responde, también, a construcciones e interrelaciones entre los distintos sujetos de la sociedad (Fraser, 1997, p. 247).
Con esto en mente, es claro que, contrario a lo que se podría pensar, la identidad no es una categoría estática y unívoca, sino contextual, sin ser relativa, pues adquiere características, matices, dependiendo de las interacciones que se van dando en cada situación en la que se ve inmerso el sujeto (sea individual o colectivo). Así pues, como lo establece Sotomayor (1998) “ningún grupo humano conforma situaciones aisladas de identidad sino que las construye en la interacción de los procesos sociales con otros grupos y las vuelve propias. La incorporación o la apropiación de elementos culturales se constituye en un elemento creativo individual y colectivo que no implica en ningún momento amalgama". La identidad tiene un proceso contextual, en constante construcción y deconstrucción, sin que esto implique que sea como una máscara, tal cual lo aclara Wade (2002, p. 256); dependiendo de la situación específica en la que se encuentre el sujeto enfatizará sobre ciertos rasgos de su identidad, se identificará de una u otra manera de acuerdo con el interlocutor y con la circunstancia en la cual se presente la interacción.

Lo anterior se contrapone, entonces, a la visión esencialista de la identidad, propia del multiculturalismo liberal, especialmente la identidad colectiva por su relación directa con las comunidades étnicas y, en el caso particular del presente artículo, las comunidades indígenas. Esta visión pretende "hacer descender la identidad colectiva de una verdad biológica que genera rasgos culturales específicos, o de una matriz histórica que marca la descendencia con una herencia común que debe permanecer inalterada, so pena 
de que los miembros potenciales del colectivo pierdan justamente su opción de colectivización y, con ello, su propia identidad" (Grueso, 2009, p. 284). De acuerdo con esto la identidad es algo inmutable, que se transmite entre generaciones de manera intacta, pues los cambios implican su pérdida. Es usual caer en el discurso esencialista de identidad étnica, bajo el cual si las comunidades no se encuentran dentro de su territorio con los elementos comunes a lo que se ha establecido como las características de la identidad -lengua, religión, territorio, etc.-, estos individuos pierden su identidad indígena.

Ahora bien, como lo establece Ariza "resulta claro que tras siglos de sometimiento, discriminación y políticas de asimilación, la identidad étnica -como indígena o como afrocolombiano- se ha convertido en una importante herramienta política y jurídica para transformar las relaciones sociales y económicas imperantes en el sector rural y agrario colombiano" (2009, p. 264). Así pues, la identidad étnica, entendida en ambos aspectos -el autorreconocimiento y el heterorreconocimiento de comunidades culturales diferentes- se constituye en un mecanismo de lucha y reivindicación de derechos y beneficios para estas comunidades tradicionalmente marginadas (Lemaitre, 2009, p. 309). A manera de ejemplo, Gros (2000, p. 63) presenta el caso de las comunidades Paéz o Nasa y Guambianos en el Cauca, quienes crearon el Consejo Regional Indígena del Cauca (CRIC) con el fin de tener representantes dentro de los concejos municipales, poniendo de presente su autorreconocimiento como comunidades indígenas ante una corporación no indígena.
De la misma forma, este discurso de la identidad esencial de lo indígena ha sido reinterpretado y reincorporado por muchas comunidades, con lo cual se ha convertido en una herramienta, un puente para conseguir su preservación y autonomía, un acto de reivindicación de los derechos que a través de la historia les han sido vulnerados, y dentro de estos especialmente los referentes a la autodeterminación y a la restitución de sus tierras o territorios ancestrales. La construcción de esta alteridad ha sido la forma de identificar y clasificar; a partir de la diferencia se han construido categorías y límites identitarios que han permitido la consolidación del movimiento indígena y la reclamación de sus derechos (Ariza, 2009, pp. 254-269). ${ }^{12}$

\section{A. Identidad jurídica: elemento subjetivo y objetivo}

A partir del desarrollo de la política de reconocimiento y respeto del contexto multicultural en la Constitución de 1991, el sistema legal colombiano se ha ocupado de construir un sujeto jurídico específico que responda a su idea del deber ser de la identidad indígena. Como determina Ariza, "dentro del pensamiento legal actual, la identificación del carácter personal del individuo es un paso anterior a la asignación de una posición dentro del sistema jurídico" (2009, p. 274). De esto se desprende que la determinación de

12 Así, se rescata de la Gaceta Constitucional las intervenciones de quienes representaron la voz de las comunidades indígenas en la Constituyente de 1991, quienes hicieron especial énfasis en una innegable diferencia, que justifica el trato distinto y, por ende, la creación de instituciones y políticas que tengan un enfoque diferenciado, diseñadas a partir de la particularidad del sujeto indígena, con su complejidad individual y colectiva. Ver Ariza (2009, pp. 254-269). 
quién es el individuo dentro del ordenamiento jurídico depende de las características que se le asignen. ${ }^{13} \mathrm{~A}$ su vez, quién es, viene de la mano de qué derechos y qué obligaciones tiene. Esta identificación se convierte entonces en una necesidad del ordenamiento, para operar de una u otra forma ante la diversidad de sujetos que se aproximan a él.

Se considera, entonces, que son dos los criterios de construcción doctrinaria que permiten definir si una persona puede identificarse y constituirse como indígena. El primero es el llamado elemento subjetivo de la identidad, "el cual oscila entre la identificación de una supuesta pertenencia "racial" - color de piel, rasgos físicos, tipo de sangre- y la autodefinición o conciencia de ser indígena" (Ariza, 2009, p. 275). Este criterio recae en el sujeto, en su presencia física compuesta de rasgos particulares pero, además, en la autoidentificación como miembro de una comunidad con prácticas culturales indígenas.

El segundo criterio se conoce como el elemento objetivo de la identidad indígena, entendido como "la existencia material y comprobable de una comunidad indígena que reproduce el pasado y la tradición dentro de un territorio. De esta forma, una persona sería indígena si se encuentra inserta en el territorio y reproduce fielmente ciertas prácticas que se consideran constitutivas de una comunidad "ancestral""

13 Un ejemplo claro lo constituyen las personas que han sido cobijadas por la medida de interdicción, quienes después de esto pierden su capacidad jurídica y, por consiguiente, su papel en el contexto jurídico cambia. De igual forma, en el caso de los menores de edad, estos tienen más restricciones y más protección que las personas mayores de 18 años.
(Ariza, 2009, p. 275). Esta existencia comprobable se ha traducido en la necesidad de reconocimiento por parte del Estado colombiano, particularmente en la División de Asuntos Étnicos del Ministerio del Interior. En términos jurídicos, para poder hablar de una comunidad indígena y de la existencia de los sujetos que la conforman es necesario un registro o algún tipo de reconocimiento por parte de esta División. Para el derecho, definir, limitar y enmarcar esa "identidad indígena” resulta fundamental en cuanto a que "ser o no ser" indígena otorgará ciertos beneficios y prerrogativas jurídicas.

En este punto es necesario mostrar la posición de la Corte Constitucional en lo que respecta a la identidad de los pueblos indígenas. Esta entidad establece que hoy en día "Los grupos étnicos, calificados hace un siglo como "salvajes", son considerados por la Constitución actual como comunidades culturales diferentes, y las personas que las constituyen, en consecuencia, tratadas como portadoras de otros valores, con otras metas y otras ilusiones que las tradicionalmente sacralizadas con el sello de Occidente" (Corte Constitucional. Sentencia C-139 de 1996). Se determina, así, la identidad indígena a partir de la alteridad, y se la define desde su diferencia con Occidente. Por esto, ahora es el antropólogo quien debe conocer y reconocer, por su experticia, la verdadera identidad indígena. Lo anterior es bastante problemático, pues como lo establece Ariza (2009), el peritaje antropológico y el desarrollo de la normatividad y operación judicial se ha centrado en quién conserva mejor sus usos y costumbres, o al decir de Lemaitre (2009, p. 300), quién parece más “indígena de 
museo". Se ha llegado a un punto en el cual la identificación válida es la heteroidentificación propuesta por el perito experto antropólogo, sin necesariamente escuchar al individuo que está siendo puesto en tela de juicio. Esta concepción que se gesta dentro del discurso del multiculturalismo liberal exalta la diferencia y trata de mantenerla a toda costa, lo que eventualmente deriva en una segregación.

\section{B. Debate sobre la identidad indígena en contextos urbanos}

La forma tradicional de entender la identidad indígena relaciona a las comunidades, de manera automática, con sus resguardos particulares, con la vida rural. Así, desde la perspectiva del desplazamiento forzado y la noción tradicional del deber ser indígena, aquellos que se identifiquen como tal no deben habitar las ciudades; son seres propios del campo y deben mantenerse en las reservas y resguardos, pues "es en estos espacios en donde su cultura se encuentra enraizada. Allá están los referentes materiales y simbólicos que nutren sus tradiciones" (Bonilla, s. f., p. 2).

Al respecto, conviene referir lo expuesto por Margarita Rosa Serje (2002, pp. 313-325) en su texto Medio ambiente, donde explica muy bien la conceptualización naturalizadora de las comunidades tradicionales: "Ios indígenas y en general los grupos "tradicionales" se conciben, como primitivos y primigenios. Así los indígenas americanos, los pastores nómadas del África o los campesinos de la "Francia profunda", se ven conceptualizados como "gentes naturales" pues este fenómeno de naturalización de paisajes y sociedades se ha visto extendido a todas aquellas regiones y localidades del planeta que encarnan el estereotipo de lo natural". Se tiene que el indígena que se moviliza hasta la capital está fuera de su contexto, de la zona que le es propia. Ya no es él en su espacio. Esto, en tanto se ha reducido su lugar a lo natural, ${ }^{14}$ a lo rural, haciendo de él un extranjero, un extraño en la ciudad.

Entonces, al hacer una comparación entre un territorio indígena y la ciudad de Bogotá, es evidente que la segunda es un espacio heterogéneo, estratificado y densificado, mientras que lo que se concibe como un resguardo indígena no opera de la misma forma. De acuerdo con Cordera y Ziccardi (2008) "las formas de propiedad y el uso de espacios reflejan el estadio de la convivencia, la distribución del ingreso y las oportunidades. La función que se asigna al espacio expresa jerarquía y forma una gran diversidad de identidades. Según Marcus, el espacio urbano se encuentra fragmentado por diversos sectores sociales y económicos" (2008, p. 10). Esto muestra la necesidad de un cambio en las prácticas y dinámicas socioculturales de la comunidad indígena víctima del desplazamiento. Su forma de subsistencia debe cambiar, igual que el medio de transporte, las distancias, las horas de trabajo y de ocio; la base de lo cotidiano debe transformarse para adaptarse a las necesidades de la urbanidad. Así, Bonilla (s. f.), al citar el caso de los Mapuches urbanos en

14 En este sentido, ver lo expuesto por Bonilla (2005). Así mismo es pertinente rescatar las críticas planteadas por Bocarejo (2011, p. 4) a la espacialización de la diferencia y la identidad indígena. 
Chile, deja claro que hay una diferencia entre el indígena metropolitano, como le llama, y el indígena que habita su resguardo, pues aquel está mucho más permeado de la cultura mayoritaria; sin que esto implique la pérdida de la identidad indígena, es una mutación, una forma de representación de la misma identidad.

El contexto urbano es muy distinto al rural, de eso no hay duda; las prácticas culturales deben mutar, pues se vuelve casi imposible cazar y recoger, o cumplir con todos los rituales religiosos en una localidad como Ciudad Bolívar, San Cristóbal o Bosa, de Bogotá. Eso explica por qué las familias indígenas migrantes suelen juntarse alrededor de cabildos para adquirir reconocimiento estatal y con ello protección en salud, educación y vivienda (en algunos casos). Según las estadísticas, en la capital de la República se encontraban, a 2005, un total de 15.033 indígenas urbanos (DANE, 2005), constituidos legalmente en los respectivos cabildos, sin tener en cuenta los no registrados por diversas causas (Molina, 2007, p. 106). Sin embargo, de acuerdo con sus propias palabras, la condición de estar en la urbanidad, de salir de su condición inicial a un medio particularmente diferente $y$, podría asegurarse, hostil, no altera su identidad indígena:

No, porque uno, su origen de ser indio no lo deja de ser sino hasta el día que se muere, así se vaya uno para otro país, uno sigue siendo indio. Si yo llevo veinte años de estar en Bogotá, yo no soy rolo, sigo siendo indio, hasta el día que me muera, porque ni la sangre mía, ni el cuero mío me lo van a cambiar, siguen siendo indios (entrevista a José Ermides Aguja Yate, gobernador del Cabildo Ambicá Pijao, 2006. En Molina, 2007, p. 110).

La identidad, según este aparte, es algo que se lleva en la sangre, algo con lo que se nace y de lo que no se puede desprender. Así, aunque no se cumpla con las características tradicionales de territorio, lengua, prácticas socioeconómicas de alimentación, entre otras, no se deja de ser indígena. La identidad cambia, no es exactamente igual, trayendo de nuevo lo expuesto por Bonilla (s. f.); 15 pero contrario a su posición, este cambio no implica la pérdida de esta.

De este aparte es posible extraer dos puntos importantes. En primer lugar, el gobernador del cabildo muestra que aunque la identidad cambia, pues se encuentra en otro contexto, es algo que está más allá del poder de decisión del individuo, no es posible aculturarse por completo, ni hacia lo "occidental-blanco" ni hacia lo indígena. En segundo lugar, es posible afirmar que de lo anterior deviene que la identidad no recae en la autoidentificación, sino en la pertenencia a un grupo indígena desde el nacimiento.

15 Este autor, con respecto al caso de la comunidad Mapuche en Chile, en el contexto urbano, afirma: "se postulaba que por el hecho de que el Mapuche en la ciudad no desarrollaba su componente espiritual, se llegó a plantear que de alguna manera dejaba de ser Mapuche... [Sin embargo] el proceso de desarrollo organizacional y creación de identidad en la ciudad demostró que las fuerzas de Futa Chaw-Kuze Ñuke están distribuidas en todas partes y se pueden desarrollar. Esta nueva realidad requiere la determinación de espacios territoriales especiales para el desarrollo de la actividad espiritual, para la realización de "nguillatun" dotado de su rewe y su bandera correspondiente... Hemos desarrollado nuestro propio "newen" su propia fuerza espiritual, naturalmente en relación y retroalimentación con la Lof, las comunidades rurales, al igual que los Lonko antiguos, los Ulmen que viajaban de la zona de Temuco al otro lado de la cordillera, al puel mapu y después regresaban a su admapu; hoy, los Mapuche urbanos viajan a sus tierras ancestrales". 
Siguiendo con esta posición, de acuerdo con Cárdenas et al. (2011) “un elemento muy importante en el proceso de reconstrucción de la identidad es la diferenciación de otros grupos o comunidades". Esto se evidencia en los casos anteriormente mencionados, en los que muchas de las comunidades en situación de desplazamiento han enfatizado las diferencias culturales visibles e invisibles como forma de mantener su identidad. El acto de llevar la vestimenta propia de la comunidad, hablar en su lengua (entre ellos) y realizar actividades que les son propias (como el tejido de collares, pulseras, cinchones y otros, entre las mujeres Emberá16) son formas de reafirmar y enfatizar la identidad indígena (Wade, 2002, p. 256) sin ser las únicas. Esto responde a varias razones: afán de autodeterminación, necesidad de fácil identificación ante el Estado, reivindicación de la identidad del sujeto individual y colectivo, entre otras.

Esta convicción les permite separar la identidad de la condición material de existencia, abriendo la puerta a la posibilidad de ser indígenas dentro del contexto urbano, de ejercer las actividades propias de la urbe y no necesariamente vendiendo lo que tradicionalmente saben hacer, como es el caso de las mujeres Emberá que venden sus tejidos en el centro de Bogotá. En síntesis, se nace con la identidad indígena y esta, sin ser absolutamente inmutable, se conserva a pesar del cambio situacional.

16 No es objeto de este trabajo discernir sobre las prácticas que fueron impuestas en la Colonia y ahora forman parte de la tradición cultural, como lo es el tejido para las mujeres Emberá.
Sin embargo, como ya se mostró, la identidad es de doble vía: comprende el reconocimiento por parte de agentes externos (heterorreconocimiento) y el autorreconocimiento, entendido como la identificación que se dan los sujetos que hacen parte de la comunidad. Estas dos visiones sobre el mismo punto entran en contraposición en términos de legitimidad de la identidad. De acuerdo con Jenkins, citado por Sinigüí (2007):

El cuestionamiento de la distinción entre grupo y categoría -o, de forma más escueta, entre autodeterminación y dominación- pone de presente la importancia del poder en los procesos de identificación [colectiva]. La dimensión externa -o categórica- de los procesos de identificación no solo es de gran relevancia sino que ha sido dejada de lado en la mayoría de trabajos donde se teoriza sobre la identidad social. La auto-identificación es sólo una parte de la historia (y no necesariamente la más importante".

Lo anterior pone de presente la importante diferenciación entre aquellos indígenas que por factores ajenos a su voluntad, como lo es el desplazamiento causado por el conflicto nacional, se ven forzados a migrar y aquellos de cabildos indígenas producto de fenómenos de reemergencia étnica, como por ejemplo, el cabildo Muisca de Bosa. En ambos casos los indígenas tienen el factor de autoidentificación y están asentados en el casco urbano, pero los primeros son reconocidos como tales, tanto por el Estado en la normatividad expedida para tratar de solucionar el fenómeno del desplazamiento con un enfoque diferencial étnico y cultural como por la 
sociedad civil, mientras que los segundos (cabildo Muisca de Bosa y otros) el Estado no siempre los reconoce, ni la mayoría de la sociedad civil los concibe como indígenas auténticos (Molina, 2007, p. 106). Esta segunda comunidad evidencia los límites de la asunción esencialista de la identidad, ya sea por entenderla limitada al contexto en el cual se nació, o por entender que identidad responde solamente a unos criterios verificables objetivamente. Estas visiones dejan de lado fenómenos existentes que reivindican el resurgimiento de identidades que se creían extintas, a partir de la sola autoidentificación, sin hacer esta identidad menos legítima o válida (Molina, 2007, p. 107).

\section{REPARACIÓN PARA EL DAÑO CUL- TURAL COLECTIVO PRODUCTO DEL DESPLAZAMIENTO FORZADO}

Así las cosas, la consecuencia clara del desplazamiento forzado, trátese o no de comunidades indígenas, es el cambio abrupto de contexto y de forma de vida. Sea que el desplazamiento se produzca dentro del mismo sector, a otro municipio o a la capital, variará la manera en que los individuos deben relacionarse con y dentro del nuevo entorno. Esto genera distintos cambios en las prácticas culturales y, en consecuencia, abre un panorama de múltiples formas a las que las identidades individual y colectiva pueden mutar.

En particular, con respecto a la presencia de comunidades indígenas en situación de desplazamiento en el área urbana, la Corte ha tendido a tomar una posición que apoya la necesidad de retorno y restitución de los terrenos que les fueron despojados, poniendo de presente su situación, que como ya se explicó es tratada en el auto 004 de 2009, y el evidente requerimiento de especial protección y salvaguarda por parte del Estado. Siguiendo con la posición de la Corte, y en consideración a que los procesos de restitución de tierras se han enfocado primordialmente en propiedades individuales, conviene traer a colación lo propuesto por Rodríguez y Lam (2010), quienes consideran que debe incluirse la justicia étnica colectiva ${ }^{17}$ para de esta forma enfocar adecuadamente la restitución a comunidades indígenas. ${ }^{18}$

Lo anterior, teniendo en cuenta que el desplazamiento de comunidades indígenas no solo afecta al sujeto individual, sino que tiene profundas consecuencias en la identidad del sujeto colectivo y su relación con el territorio donde habitan. Así, se busca mitigar este impacto y corregir el daño mediante el reconocimiento cultural. En este punto es útil anotar que la idea de justicia étnica colectiva va más allá de la simple reparación del daño y la restitución a un estado anterior. Busca aprovechar el momento coyuntural y abrir espacios para la corrección de inequidades e injusticias sociales más profundas. Es más cercano a un enfoque transformador, como lo denominaron Uprimny y Saffon (2008), lo que implica la transformación de situaciones de marginalidad y exclusión social previas al desplazamiento.

17 Definida en el texto como "aquella que recae sobre territorios comunales que sirven como espacio de ejercicio y afirmación de la cultura de una colectividad" (Rodríguez y Lam, 2010, p. 16) 
De esta manera, si se considera que la mejor solución es la restitución, es necesario que este proceso no solo signifique el retorno al terreno del cual la comunidad fue expulsada. El artículo 28 del Decreto 4633 de 2011, como ya se vio, establece que "la reparación integral, en tanto transformadora, no se limita al resarcimiento del daño material y espiritual, o al restablecimiento de la situación anterior al hecho victimizante, sino que también se verá complementada por acciones que contribuyan a la eliminación de los esquemas de discriminación y marginación que pudieron ser la causa de los hechos victimizantes". Sin embargo, el peligro material de esta disposición se encuentra en que su contenido se limite a un carácter simbólico, como ha ocurrido en gran parte de los casos de restitución de tierras hasta ahora. ${ }^{19}$ Es imperativo realizar un proceso que, con el mismo consentimiento y participación activa de la comunidad indígena afectada, permita que el daño identitario y cultural, causado por el desplazamiento, sea reparado y que, además, permita el resarcimiento del daño histórico del cual han sido víctimas.

Ahora, es de igual manera evidente que la reparación de daños culturales e identitarios trae consigo muchas dificultades. En primer lugar se encuentra la amplitud de estos y su característica principal: son inmateriales. La pérdida de prácticas y tradiciones que ocasiona el despla-

19 Al respecto, ver el último informe (septiembre 2013) sobre retorno y restitución de tierras de Human Rights Watch para Colombia, p. 138, en referencia a la comunidad Emberá de Patadó, Chocó. Este permite ver cómo la afamada figura del retorno y la restitución para las personas víctimas del desplazamiento forzado sigue estando atravesada por hechos de violencia, amenaza y falta de respuesta y actuación estatal. La situación no parece haber cambiado sustancialmente. zamiento forzado genera múltiples escenarios posibles: comunidades que no deseen recuperarlas pues ya están asentadas en el casco urbano y no las ven como necesarias; comunidades que deseen recuperar dichas prácticas sin necesidad de volver a su territorio; comunidades que no deseen volver a su territorio pues este fue "profanado" y sus prácticas son imposibles de recuperar; comunidades que deseen recuperar sus prácticas y retornar a su territorio; entre muchas otras dentro de las cuales, muy probablemente, existen rupturas y posiciones diversas.

Sin embargo, es necesario dejar claro que el retorno inmediato no siempre es la opción más viable. En estos casos, se hace necesario acudir a mecanismos que puedan brindar protección a los individuos víctimas del desplazamiento y que, a su vez, conserven el enfoque étnico y culturalmente diferenciado. Así las cosas, como una primera medida de respuesta para las comunidades que consideren el retorno como su opción deseada, es pertinente mencionar lo propuesto en el artículo 175 del proyecto de decreto reglamentario de la Ley 1448 de 2011, elaborado por el Centro de Investigaciones Sociojurídicas - cıus- de la Universidad de los Andes. En este se propone la creación de refugios temporales de vivienda humanitaria con enfoque diferencial, los cuales tendrían el carácter de vivienda transitoria de emergencia en caso de imposibilidad de retorno inmediato, y serían construidos procurando mantener "las condiciones más similares posibles a las condiciones originales de habitación de las minorías nacionales y los grupos étnicos". 
Ahora, ¿qué sucede con los grupos indígenas que ya no desean, o no pueden acudir al retorno? En este punto resulta pertinente lo planteado por Vrdoljak (2008), quien pone de presente que en materia de reparación a daños, el mecanismo preferido es la restitución. Sin embargo, existen aspectos en los cuales esta no puede llevarse a cabo, como sucede con la afectación a la cultura y la identidad indígena, debiendo entonces acudir a la compensación, esto es, la restitución en especie o monetaria. De acuerdo con esta autora, los principios internacionales establecen que la compensación debe reflejar el daño causado. Sin embargo, lo anterior no es siempre tan sencillo ni necesariamente justo, pues están limitadas por medidas presupuestales y económicas. Como ejemplo pone de presente el caso de indígenas canadienses y australianos que fueron sustraídos de sus comunidades para ser educados por europeos católicos o cristianos, y luego indemnizados a través de fondos comunes; en su caso también se hizo un reconocimiento público del daño consumado por la actuación estatal.

La constitución de fondos comunes destinados a proveer bienestar social a la comunidad contribuye a la idea de Uprimny y Saffon de una transformación, que operaría tanto con comunidades que quieren la restitución de su territorio colectivo como con aquellas que no tengan interés en retornar al territorio del cual fueron despojados. De esta manera, se propone la compensación como método, no único ni excluyente, de reparación para daños culturales.

\section{CONCLUSIÓN}

Con todo lo anterior se pretende enfatizar que la reparación a sujetos colectivos, en este caso comunidades indígenas en situación de desplazamiento, no debe limitarse a la restitución del terreno del cual fueron desterrados, puesto que se estaría cayendo en el esencialismo que asimila indígena con resguardo, que es precisamente lo que se quiere refutar. En contraposición, se propone priorizar el criterio colectivo, en el entendido que las comunidades indígenas son, en efecto, étnica y culturalmente diferenciadas del resto de la población desplazada y, por lo tanto, su trato no debe ser estrictamente igual. No obstante, este criterio debe construirse no con fundamento ni enfoque exclusivo en las categorías subjetivamente verificables y unilateralmente construidas de la identidad fosilizada (lengua, circunscripción particular a un territorio delimitado y prácticas socioeconómicas propias de estos pueblos), sino prestando especial atención a los requerimientos y deseos particulares de cada comunidad, buscando así transformar de manera real y efectiva la marginalización, pobreza y colonialismo del que siguen siendo víctimas las comunidades indígenas.

Entonces, el concepto transformador en la reparación a estas comunidades, a la luz de la complejidad del concepto de identidad y su posibilidad de mutación, abre el panorama para poder plantear una política estatal que se desarrolle en consideración a esa variación de la identidad y que, a su vez, no implique una preferencia tácita a mantener estáticas las ca- 
racterísticas antes mencionadas, oculta en políticas que "premien" 20 esta fosilización de la identidad, sino a darles una mayor autonomía, beneficios sociales o económicos, entre otros. Será también parte de dicha política respetar la realidad compleja que muestran algunos miembros de comunidades indígenas que deciden, por múltiples razones, quedarse en los cascos urbanos, sin que esto implique para el Estado ni para la sociedad civil, la pérdida de su identidad indígena $\mathrm{y}$, por ende, de los derechos diferenciados que de esta se desprenden. En palabras de Fraser (1997, p. 249), lo ideal es "conjugar una política cultural antiesencialista del reconocimiento y una política social igualitaria de la redistribución".

Aun así, en la actualidad, pareciera ser que las comunidades indígenas mismas están más dispuestas a "ceder" parte de su identidad y su cultura, que lo que la sociedad mayoritaria y el Estado querrían permitirles mutar. Lo anterior explica por qué las instituciones públicas ven como medida ideal y primordial el retorno de estas a su territorio, sin considerar las condiciones materiales de existencia a las cuales llegarán, los daños culturales a los que se han visto expuestos, ni sus posibles intereses para establecerse en lo urbano, al tiempo que la sociedad opta por identificarlos como asimilados, aculturados y no titulares de los derechos constituidos en función de la diferencia étnica. Por

20 A manera de ejemplo se trae el artículo 27 de la Ley 48 de 1993 que establece: Están exentos de prestar el servicio militar en todo tiempo y no pagan cuota de compensación militar:

(...) b) Los indígenas que residan en su territorio y conserven su integridad cultural, social y económica. (Subraya fuera del texto original). esto, creemos que un escenario que da prelación a la autodeterminación, separándose de los elementos propios de la delimitación de la identidad que contribuyen a su visión estática y fosilizada y que, a su vez, propende por la integración de las comunidades indígenas dentro del panorama nacional, es el más propicio para la garantía de los derechos de las comunidades indígenas. Esto, en tanto permite dejar de lado la concepción esencial y estática de lo que es y lo que debe ser un indígena; que los debates giren hacia la consideración de las condiciones materiales de existencia actuales de las comunidades; y la participación de las comunidades mismas, en igualdad de condiciones, en la construcción de sus propias propuestas y su institucionalidad (onic, 2013), pues ellas son quienes deben decidir sobre su futuro identitario, no el Estado de manera unilateral.

\section{Referencias bibliográficas}

Alcaldía de Bogotá. Secretaría de Integración Social. (2012). Proyecto 747: atención diferencial en servicios sociales a comunidades étnicas. Recuperado de: http://www.integracionsocial.gov.co/anexos/documentos/proyectosbogotahumana/747\%20Atencion\%20diferencial\%20a\%20en\%20servicios\%20sociales\%20a\%20comunidades\%20etnicas.pdf

Alto Comisionado de las Naciones Unidas para los Refugiados -ACNUR-. (2012). Situación Colombia: pueblos indígenas. Recuperado de: http://www.acnur.org/t3/fileadmin/ Documentos/RefugiadosAmericas/Colom- 
bia/2012/Situacion_Colombia_-_Pueblos_indigenas_2012.pdf?view=1

Arias, F., Boada, S., Orduz, N., Rodríguez, C. y Rubiano, S. (2010). Pueblos indígenas y desplazamiento forzado. Evaluación del cumplimiento del Gobierno colombiano del auto 004 de la Corte Constitucional colombiana. Documento 3. Programa de Justicia Global y Derechos Humanos. Bogotá: Universidad de los Andes, Facultad de Derecho.

Ariza, L. J. (2009). Derecho, saber e identidad indígena. Bogotá: Universidad de los Andes, Siglo del Hombre.

Bocarejo, D. (2011). Dos paradojas del multiculturalismo colombiano. La espacialización de la diferencia indígena y su aislamiento político. Revista Colombiana de Antropología, 47(2), 97-121.

Bonilla, D. (2005). El principio de unidad política y el autogobierno de las minorías culturales. En D. Bonilla y M. A. Iturralde (Eds.). Hacia un nuevo Derecho Constitucional. Bogotá: Universidad de los Andes.

Bonilla, D. (s. f.). Indígenas urbanos y derechos culturales. Recuperado de: http://www.palermo. edu/Archivos_content/derecho/pdf/Articulo-StudyspaceDenver.pdf

Cárdenas, P., Carrasco, A. L., Hernández, C., Labastida, D., Nieves, R., Pérez, B., Ramírez, E., Sanmiguel, D. y Tortoriello, S. ( 2011). Reconstrucción de la identidad indígena en el contexto urbano: caso de los Huicholes. Mon- terrey: Instituto Tecnológico y de Estudios Superiores de Monterrey.

Carrillo, D. y Patarroyo, N. S. (Eds.). (2009). Derecho, interculturalidad y resistencia étnica. Bogotá: Universidad Nacional de Colombia.

Castellanos, G., Grueso I. D. y Rodríguez, M. (2009). Identidad, cultura y política: perspectivas conceptuales, miradas empíricas. Cali: Universidad del Valle.

Centro de Investigaciones Sociojurídicas - cıJus- . (2010). Proyecto Decreto Reglamentario: por el cual se desarrolla el artículo 205 de la Ley Número 1448 de 2011. Bogotá: Universidad de los Andes. Recuperado de: http://www.convergenciacnoa.org/files/PROYECTO_DECRETO_ClJUS_JULIO_14_2010.pdf

Colombia. Congreso de la República. Ley 1381 del 2010. Por la cual se desarrollan los artículos 7o, 80, 10 y 70 de la Constitución Política, y los artículos 4o, 50 y 28 de la Ley 21 de 1991 (que aprueba el Convenio 169 de la OIT sobre pueblos indígenas y tribales), y se dictan normas sobre reconocimiento, fomento, protección, uso, preservación y fortalecimiento de las lenguas de los grupos étnicos de Colombia y sobre sus derechos lingüísticos y los de sus hablantes. Diario Oficial $n^{\circ} .47 .603$ de 25 de enero de 2010

Colombia. Congreso de la República. Ley 1448 de 2011. Por la cual se dictan medidas de atención, asistencia y reparación integral a las víctimas del conflicto armado interno y se 
dictan otras disposiciones. Diario Oficial $n^{\circ}$ 48096 de junio 10 de 2011.

Colombia. Congreso de la República. Ley 160 de 1994. Por la cual se crea el Sistema Nacional de Reforma Agraria y Desarrollo Rural Campesino, se establece un subsidio para la adquisición de tierras, se reforma el Instituto Colombiano de la Reforma Agraria y se dictan otras disposiciones. Diario Oficial n .41 .479 , de 5 de agosto de 1994.

Colombia. Congreso de la República. Ley 387 de 1997. Por la cual se adoptan medidas para la prevención del desplazamiento forzado; la atención, protección, consolidación y estabilización socioeconómica de los desplazados internos por la violencia en la República de Colombia. Diario Oficial n. 43.091, de 24 de julio de 1997.

Colombia. Congreso de la República. Ley 48 de 1993. Por la cual se reglamenta el servicio de Reclutamiento y Movilización. Diario Oficial $n^{\circ}$. 40.777, de 4 de marzo de 1993.

Colombia. Constitución Política de 1991.

Colombia. Corte Constitucional. Auto 004 de 2009. M. P.: Manuel José Cepeda Espinosa

Colombia. Corte Constitucional. Auto 382 de 2010. Sala Especial de Seguimiento a la Sentencia T-025 de 2004. M. P.: Juan Carlos Henao Pérez, Nilson Pinilla Pinilla y Luis Ernesto Vargas Silva.

Colombia. Corte Constitucional. Sentencia
C-139 de 1996. M. P.: Carlos Gaviria Díaz.

Colombia. Corte Constitucional. Sentencia SU510 de 1998. M. P.: Eduardo Cifuentes Muñoz.

Colombia. Corte Constitucional. Sentencia T-025 de 2004. M. P.: Manuel José Cepeda Espinosa.

Colombia. Corte Constitucional. Sentencia T-402 de 2011. M. P.: Gabriel Eduardo Mendoza Martelo.

Colombia. Corte Constitucional. Sentencia T-792 de 2012. M. P.: Luis Ernesto Vargas Silva.

Colombia. Presidencia de la República. Decreto 1088 de 1993. Por el cual se regula la creación de las asociaciones de Cabildos y/o Autoridades Tradicionales Indígenas. Diario Oficial nº 40914 de junio 11 de 1993.

Colombia. Presidencia de la República. Decreto 1397 de 1996. Por el cual se crea la Comisión Nacional de Territorios Indígenas y la Mesa Permanente de Concertación con los pueblos y organizaciones indígenas y se dictan otras disposiciones. Diario Oficial $n^{\circ} .42853$ de agosto 12 de 1996.

Colombia. Ministerio de Agricultura. Decreto 2164 de 1995. Por el cual se reglamenta parcialmente el Capítulo XIV de la Ley 160 de 1994 en lo relacionado con la dotación y titulación de tierras a las comunidades indígenas para la constitución, reestructuración, ampliación y saneamiento de los Resguardos Indígenas en el territorio nacional. 
Colombia. Congreso de la República. DecretoLey 4633 de 2011. Por medio del cual se dictan medidas de asistencia, atención, reparación integral y de restitución de derechos territoriales a las víctimas pertenecientes a los pueblos y comunidades indígenas. Diario Oficial $n^{\circ} .48278$ de diciembre 9 de 2011.

Cordera, R., Ramírez, P. y Ziccardi, A. (2008). Pobreza, desigualdad y exclusión social en la ciudad del siglo XXI. Mexico: Siglo XX, Unam, Instituto de Investigaciones Sociales.

Del Cairo, C. y Rozo, E. (enero-junio de 2006). Políticas de la identidad, ciudadanía intercultural y reivindicaciones territoriales indígenas en dos localidades amazónicas. Universitas Humanística, 61, 107-134.

Fondo Indígena. (2007). Pueblos indígenas y ciudadanía "Los Indígenas Urbanos". Conferencia Internacional, Palais d'Egmont, Bruselas, 26 de marzo del 2007. Bruselas: Fondo Indígena, Cooperación Belga al desarrollo.

Fraser, N. (1997). Iustitia Interrupta: reflexiones críticas desde la posición "postsocialista". Bogotá: Siglo del Hombre Editores, Universidad de los Andes.

Fundación Hemera. (2006). Diagnóstico de grupos indígenas en Bogotá y lineamientos de política pública para la atención de grupos étnicos.

Gros, C. (1991). Colombia indígena: identidad cultural y cambio social. Bogotá: Fondo Editorial Cerec.
Gros, C. (2000). Políticas de la etnicidad: identidad, Estado y modernidad. Bogotá: Instituto Colombiano de Antropología e Historia (ICANH).

Grueso, D. (2009). Identidades étnicas, justicia y política transformativa. En Castellanos, G., Grueso, D y Rodríguez, M. (comp.). Identidad, cultura y política: perspectivas conceptuales, miradas empíricas (pp. 283-307). Cali: Programa editorial Universidad del Valle.

Human Rights Watch. (2013). El riesgo de volver a casa: violencia y amenazas contra desplazados que reclaman restitución de sus tierras en Colombia. Estados Unidos: Autor.

Instituto Colombiano de Antropología. (1998). Modernidad, identidad y desarrollo. Bogotá: Instituto Colombiano de Antropología, Colciencias.

Kloosterman, J. (1997). Identidad indígena: entre romanticismo y realidad. Amsterdam: Thela Publishers.

Kymlicka, W. (2006). Ciudadanía multicultural. Barcelona: Paidós.

Lemaitre, J. (2009). El derecho como conjuro: fetichismo legal, violencia y movimientos sociales. Bogotá: Siglo del Hombre Editores, Universidad de los Andes.

Lentin, A. y Titley, G. (2011). The Crisis of Multiculturalism. Racism in a Neoliberal Era. London: Zed Books. Selección. 
Marcuse, H. (1954). El hombre unidimensional. Ensayo sobre la ideología de la sociedad industrial avanzada. Barcelona: Planeta-DeAgostini.

Molina, H. (Abril, 2007). Nuevos escenarios de vida indígena urbana: el caso de Bogotá. Etnias \& Política, 4, 100-115.

Olive, L. (2008). Interculturalismo y justicia social. México: Unam. Programa Universitario México Nación Multicultural, Dirección General de Publicaciones y Fomento Editorial.

Organización Internacional del Trabajo. Convenio 107 de 1957. Acerca de los derechos de las poblaciones indígenas y tribales. Aprobado por Colombia mediante Ley 31 de 1967.

Organización Internacional del Trabajo. Convenio número 169. Sobre pueblos indígenas y tribales en países independientes adoptado por la $76^{a}$ reunión de la conferencia general de la oı, Ginebra 1989, aprobado por Colombia mediante Ley 21 de 1991.

Organización Nacional Indígena de Colombia -onic-. (2013). La construcción de la paz en Colombia: un propósito que trasciende la negociación política. Propuestas desde el movimiento indígena colombiano. Ponencia en el $\mathrm{X}$ Conversatorio de la Jurisdicción Constitucional "Diálogo Constitucional para la Paz". Medellín, septiembre 20 de 2013.

Rodríguez, C. (Coord.). (2010). Más allá del desplazamiento: políticas, derechos y superación del desplazamiento forzado en Colombia. Bo- gotá: Universidad de los Andes, Facultad de Derecho, Ediciones Uniandes.

Rodríguez, C. y Lam, Y. (2010). Etnorreparaciones. La justicia colectiva étnica y la reparación a pueblos indígenas y comunidades afrodescendientes en Colombia. Bogotá: Dejusticia.

Secretaría de Integración Distrital. (Septiembre, 2011). Formulación participativa de la política pública distrital para el reconocimiento, garantía, protección y restablecimiento de derechos de los pueblos indígenas en Bogotá. Recuperado de: http://www.integracionsocial. gov.co/anexos/documentos/polpublicas/politica indigena.pdf

Serje de la Ossa, M. (2002). Medio ambiente. En Palabras para Desarmar. Una aproximación crítica al vocabulario del reconocimiento cultural en Colombia. Bogotá: Ministerio de cultura, ICANH.

Sevilla, M. (Enero-Junio, 2007). Indígenas urbanos y las políticas del reconocimiento dentro del contexto colombiano. Perspectivas Internacionales, 3(1), 7-24.

Sinigüí, S. (Septiembre-Diciembre, 2007). ¿Es posible ser indígena en la ciudad? Sobre estudios indígenas y afrocolombianos. Memoria Personal. Educación y Pedagogía, 49.

Sotomayor, M. L. (1998). Porque somos indígenas, pero ¿por qué somos indígenas? En Sotomayor, M. L. (ed.). Modernidad, identidad y desarrollo (pp. 399-423). Bogotá: Instituto Colombiano de Antropología. 
Taylor, C. (1931). Fuentes del yo: la construcción de la identidad moderna. Barcelona: Paidós.

Unidad para la Atención y Reparación Integral a las Víctimas. (2012). Informe de gestión. Recuperado de: http://www.accionsocial.gov.co/ documentos/7514_Informe_de_Gesti\%C3\%B3n Unidad_V\%C3\%ADctimas_-_dic31_31ene.pdf

Uprimny, R. y Saffon, M. P. (2008). Reparaciones transformadoras, justicia distributiva y profundización democrática. En: Reparar en CoIombia: los dilemas en contextos de conflicto, pobreza y exclusión. (pp. 31-70). Bogotá: ICTJ y DeJuSticia.
Villa, W. y Houghton, J. (2005). Violencia política contra los pueblos indígenas en Colombia: 1974-2004. Bogotá: Cecoin y oIA.

Vrdoljak, A. F. (2008). Reparations for Cultural Loss. En F. Lenzerini (Ed.). Reparations for Indigenous Peoples in International and Comparative Law. Oxford: Oxford University Press.

Wade, P. (2002). Identidad. En Palabras para Desarmar. Una mirada crítica al vocabulario del reconocimiento cultural. Bogotá: Ministerio de cultura, ICANH. 